\title{
Dead sea like giant negative $t$ wave associated with subarachnoid hemorrhage
}

\author{
Recep Kurt ${ }^{1}$, Hakan Güneş ${ }^{1}$
}

1) Sivas Numune Hospital, Department of Cardiology, MD, Sivas, Turkey

\begin{abstract}
Subarachnoid hemorrhage is a catastrophic neurological event. Rupture of an aneurysm results it. In addition to neurological signs and symptoms ECG abnormalities reported. These ECG findings reported are prolonged QTc, ST segment abnormalities, T wave inversion, abnormal $\mathrm{U}$ wave, bradicardia, tachicardia, Premature ventricular complex, Premature atrail complex, atrial fibrilation, VT, AV blocks. We described a patient with subarachnoid hemorrhagae showed giant inverted $\mathrm{T}$ wave.
\end{abstract}

Keywords: Subarachnoid hemorrhage, $\mathrm{T}$ wave inversion

Kurt R., Güneş H., Dead sea like giant negative t wave associated with subarachnoid hemorrhage. EJCM 2017; 05 (2): 37-40. Doi: 10.15511/ejcm.17.00237. 


\section{Introduction}

Subarachnoid hemorrhage is a catastrophic neurological event. Rupture of an aneurysm results it. In addition to neurological signs and symptoms ECG abnormalities reported. These ECG findings reported are prolonged QTc, ST segment abnormalities, T wave inversion, abnormal U wave, bradicardia tachicardia, Premature ventricular complex, Premature atrail complex, atrial fibrilation, VT, AV blocks. We described a patient with subarachnoid hemorrhagae showed giant inverted $\mathrm{T}$ wave. Generally inverted $\mathrm{T}$ waves are related with acute coronary syndromes. Addionally, T wave inversion occurs in patients with left ventricule hypertrophy, acute myocarditis, WPW sydnrome, acute pulmonary embolism, pericarditis, electrolit disturbances, on treatment with digoxin and Yamaguchi syndrome.

\section{Case Report}

64-year old woman admitted to the emergency department with sudden loss of consciousness and left hemiparesis. The blood pressure was $180 / 120 \mathrm{mmHg}$ with a heart rate of $78 \mathrm{bpm}$. Her ECG showed global very widely splayed and very deeply inverted T-waves with prolonged QT (QTc: $640 \mathrm{~ms}$ ) (Figure 1). Cranial CT showed subarachnoid hemorrhage.

Standard biochemical parameters were in normal limits except serum potassium level of $3.1 \mathrm{mg} / \mathrm{dL}$ and leukocytosis on complete blood count. Bilateral basal crackling rales in the lungs were detected but the echocardiography, cardiac markers and the renal parameters were all in normal limits. The patient was entubated after a short period after admission and she died after a short time of deterioration.

\section{Discussion}

$\mathrm{T}$ wave is the electrocardiographic manifestation of ventricular repolarization. Any reason disrupting ventricular repolarisation just like acute coranary syndromes, left ventricular hypertrophy, pulmonary embolism, electrolyte disturbances and cerebrovascular events eventuate $\mathrm{T}$ wave abnormalities. Subarachnoid hemorrhage is usually accompanied by electrocardiographic abnormalities including the T-wave abnomalities he and it's thought that these changes are caused by increased sympathetic and vagal tone leading to aberrant repolarisation, probably secondary to myocyte injury and contraction band necrosis. ${ }^{1}$

Neurogenic ECG alterations are often transient. It causes diagnostic problems, ECG findings in neurogenic problems can mimic acute myocardial infarction. It is important to avoid inappropriate therapies. An imbalance of autonomic cardiovascular control and increased

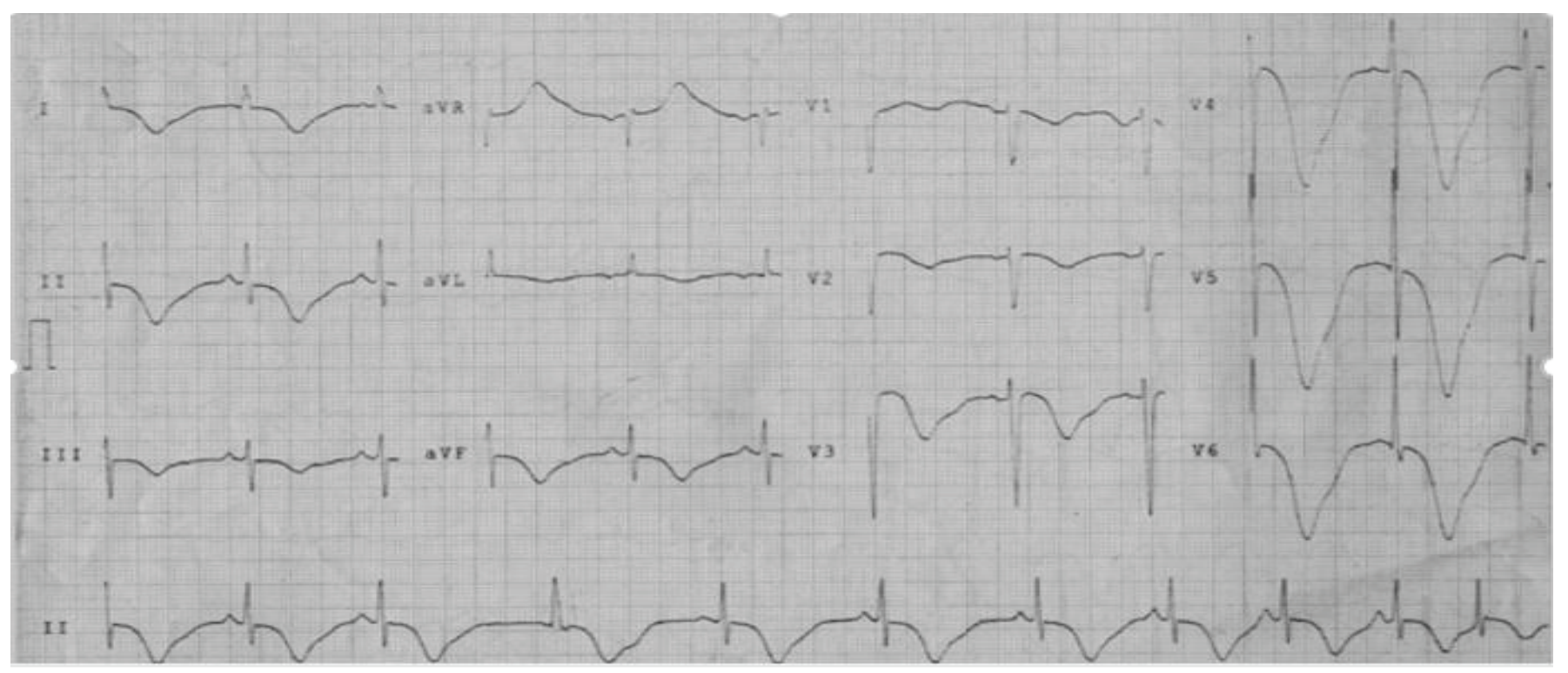

Figure 1: Her ECG showed global very widely splayed and very deeply inverted T-waves with prolonged QT 
circulating local myocardial tissue catecholamines. Several experience investigation reported that a sudden increase in intracranial pressure occurs that a massive sympathetic discharge. ${ }^{2,3}$ Experimental studies suggest that a large amount of norepinephrin is released during sudden neurologic problems. Alterations in cardiac depolarisation and repolarisation reported $74 \%$ of patient with cerebrovascular events. ${ }^{4}$ Experimental studies impilicates that insular cortex is responsible in cardiovascular control and heart chronotropik organisation.

Studies suggest that its involvement occurs neurogenic ECG alterations. ${ }^{5}$ Porter et al. ${ }^{6}$ found that stimulation of the posterolateral hypothalamus not only induced rhythm abnormalities but also caused repolarisation changes. Attar and collegues found that stimulation of the anterior hypothalamus produced ST elevation and deepening of T waves. ${ }^{7}$ Thus, hypothalamic stimulation is capable of causing both arrhythmias and a variety of ECG changes which mimic acute myocardial injury or ischemia. In a study by Estanol et al. ${ }^{8}$ rhythm and repolarisation changes were created in dogs by introducing blood into the subarachnoid space.

Rudehill et al. ${ }^{9}$ ECG s were prospectively studied on 406 patients with subarachnoid hemorrahagiae. Three hundred thirty one patients (82\%) had an abnormal ECG. The predominant findings were $\mathrm{U}$ wave changes (47\%). T wave abnormalities (32\%), prolonged QTc interval (24\%), and ST segment depression.( $15 \%)$. Stober et al. ${ }^{10}$ showed that ECG abnormalities in patients with subarachnoid hemorrahagiae were interested in arterial spasm on the brain. Several studies revealed electrocardiographic abnormalities related with subarachnoid hemorrahagiae. ${ }^{11-13}$

In conclusion; acute ischemic cardiac events show electrcardiographic abnormalities. $\mathrm{T}$ wave abnormalities also can often seems as a result of acute cardiac problems. On the other hand acute cerebrovascular events can mimic electrocardiographic abnormalities in patients with acute cardiac problems. As a result phsician must be aware about these ECG similarities. Otherwise, these ECG abnormalities can cause inappropriate therapies. 


\section{References}

1. Hironosuke Sakamoto, Hiroshi Nishimura, Kouji lmataka. Abnormal Q Wave, ST-Segment Elevation, T-Wave Inversion, and Widespread Focal Myocytolysis Associated With Subarachnoid Hemorrhage. Jpn Circ J 1996; 60: 254-7.

2. Nathan MA, Reis DJ.Fulminating arterial hypertension with pulmonary edema from release of adrenomedullary catecholamines after lesions of anterior hypothalamus in the rat. Circ Res

3. Hoff JT, Nishimura M, Garcia Uria J, Miranda S.Experimental neurogenic pulmonary edema, Part 1: The role of systemic hypertension. J Neurosurgery 1986; 226-35.

4. Oppenheimer SM, Cechetto DF, Hochinski VC, Cerebrogenic cardiac arrhythmias,Cerebral elevtrocardiographic influences and their role in sudden death.Arch Neurol 1990; 47: 513-9.

5. Tokgözoğlu SL, Batur MK, Topçuoğlu MA. Effects of stroke localization on cardiac autonomic balance and sudden death.Stroke 1999; 30: 1307-11.

6. Porter RW, Kamikana K, Greenhoot JH: Persistent electrocardiographic abnormalities experimentally induced by stimulation of the brain.Am Heart J 1962; 64: 815-9.

7. Attar HJ, Gutierrez MT, Bellet S: Effects of stimulation of hypothalamic and reticular activating systems on production of cardiac asshythmias. Circ Res 1963; 12: 14-21.

8. Estanol BV, Loyo MV,Mateos JH: Cardiac arrhythmias in experimental subarachnoid hemorrhage.Stroke 1977; 8: 440-8.

9. Rudehill A.Olsson GL, Sundquist K: ECG abnormalities in patients with subarachnoid hemooohage and intracranial tumors. J Neurol Neurusurg Psychiatry 1974; 50: 1375-81.

10. Stober T, Kunze K. Electrocardiographic alterations in subarachnoid haemorrhage. Correlation between spasm of the arteries of the left side on the brain and T inversion and QT prolongation. J Neurol 1982; 227 : 99-113.

11. van Bree MD, Roos YB, van der Bilt IA, Wilde AA, Sprengers ME, de Gans K, Vergouwen MD. Prevalence and characterization of ECG abnormalities after intracerebral hemorrhage. Neurocrit Care. 2010; 12: 50-5.

12. Brunninkhuis LG. Electrocardiographic abnormalities suggesting myocardial infarction in a patient with severe cranial trauma. Pacing Clin Electrophysiol 1983; 6: 1336-40.

13. Wittebole X, Hantson P, Laterre PF, Galvez R, Duprez T, Dejonghe D, Renkin J, Gerber BL, Brohet CR. Electrocardiographic changes after head trauma. J Electrocardiol 2005; 38: 77-81.

Received: 09/07/2016

Accepted: 30/03/2017

Published: 15/06/2017

Disclosure and conflicts of interest:

Conflicts of interest were not reported.

\section{Corresponding author:}

Dr. Hakan Güneş

Mail: drhakangunes83@hotmail.com 